Article

\title{
Effect of Preliminary Alkali Desilication on Ammonia Pressure Leaching of Low-Grade Copper-Silver Concentrate
}

\author{
Kirill Karimov ${ }^{1}$, Andrei Shoppert ${ }^{1, *} \mathbb{C}$, Denis Rogozhnikov ${ }^{1} \mathbb{D}$, Evgeniy Kuzas ${ }^{1}$, \\ Semen Zakhar'yan ${ }^{2}$ and Stanislav Naboichenko ${ }^{1}$ \\ 1 Department of Non-ferrous Metals Metallurgy, Ural Federal University, 620002 Yekaterinburg, Russia; \\ kirill_karimov07@mail.ru (K.K.); darogozhnikov@yandex.ru (D.R.); e.kuzas@ya.ru (E.K.); \\ ssnaboichenko@mail.ru (S.N.) \\ 2 TOO Kazgidromed, Karaganda 100009, Kazakhstan; szakharyan@yandex.kz \\ * Correspondence: andreyshop@list.ru; Tel.: +7-9220243963
}

Received: 19 May 2020; Accepted: 15 June 2020; Published: 18 June 2020

check for updates

\begin{abstract}
Ammonia leaching is a promising method for processing low-grade copper ores, especially those containing large amounts of oxidized copper. In this paper, we study the effect of Si-containing minerals on the kinetics of $\mathrm{Cu}$ and Ag leaching from low-grade copper concentrates. The results of experiments on the pressure leaching of the initial copper concentrate in an ammonium/ammonium-carbonate solution with oxygen as an oxidizing agent are in good agreement with the shrinking core model in the intra-diffusion mode: in this case, the activation energies were $53.50 \mathrm{~kJ} / \mathrm{mol}$ for $\mathrm{Cu}$ and $90.35 \mathrm{~kJ} / \mathrm{mol}$ for Ag. Energy-dispersive X-ray spectroscopy analysis (EDX) analysis showed that reagent diffusion to $\mathrm{Cu}$-bearing minerals can be limited by aluminosilicate minerals of the gangue. The recovery rate for copper and silver increases significantly after a preliminary alkaline desilication of the concentrate, and the new shrinking core model is the most adequate, showing that the process is limited by diffusion through the product layer and interfacial diffusion. The activation energy of the process increases to $86.76 \mathrm{~kJ} / \mathrm{mol} \mathrm{for} \mathrm{Cu}$ and $92.15 \mathrm{~kJ} / \mathrm{mol}$ for Ag. Using the time-to-a-given-fraction method, it has been shown that a high activation energy is required in the later stages of the process, when the most resistant sulfide minerals of copper and silver apparently remain.
\end{abstract}

Keywords: ammonia leaching; high-pressure leaching; copper extraction; silver extraction; desilication; kinetics

\section{Introduction}

The depletion of reserves of high-quality raw materials of non-ferrous metals is an increasingly significant problem around the globe today. As a result, low-grade ores and concentrates are involved in processing [1,2], and enterprises have to sacrifice recovery and quality to maintain the required levels of productivity.

The deterioration of technological parameters and indicators is due to a decrease in the content of valuable components and an increase in harmful impurities, along with the fact that non-ferrous and noble metals often exist in minerals as fine impregnations in gangue with mutual intergrowth and the presence of nanodispersed, colloidal grains, etc. [3,4].

Traditional methods of processing and the beneficiation of such raw materials are characterized by significant losses, since such finely disseminated components cannot be separated and recovered to an acceptable degree to obtain monometallic concentrates and intermediates, which leads to significant losses of valuable metals and the stockpiling of various industrial products and waste. 
At the same time, the use of such off-balance materials in processing can increase the term of exhaustion of natural resources by several times, which is greatly important for sustainable economic development and environmental safety. Therefore, science and industry are in a constant search for new effective ways of processing such troublesome raw materials.

Currently, the world has developed a large number of diverse technologies for processing such complicated raw materials. The most common technologies involve the ultrafine grinding of raw materials [5-7]; various versions of hydrochemical oxidation with different oxidizing agents, including microorganisms [8-11], nitric acid and its decomposition products [12-15]; processes at elevated temperatures and pressures [16,17]; and combined technologies with various types of preliminary roasting, which are less and less popular due to environmental problems and low technical and economic indicators [18,19].

One of the most widespread technologies in the industry involves sulfuric acid and neutral pressure leaching for the quantitative oxidation of sulfides containing valuable metals (pyrite, arsenopyrite, chalcopyrite, etc.), followed by the cyanidation of the obtained cakes to recover noble metals and non-ferrous metals from solutions [20]. The recovery of silver by cyanidation from sulfuric acid autoclave leachates is difficult due to intergrowths with quartzite and the formation of argentojarosite, inert with respect to the cyanide ion [21]. Therefore, leaching in ammonia media can be used to avoid the formation of argentojarosite and to increase the degree of silver recovery directly at the pressure-leaching stage [22].

Ammonia has been widely used as an effective leaching agent in many hydrometallurgical processes over many years. Ammonia can be used to leach base metals ( $\mathrm{Cu}, \mathrm{Ni}, \mathrm{Co}$ and $\mathrm{Zn})$, as well as precious metals $(\mathrm{Ag}$ and $\mathrm{Au}$ ), owing to the formation of soluble and very strong ammonia complexes. Various ammonium salts [23] can act as complexing agents. For example, for sulfide copper minerals and silver, the formation of complexes can be represented as follows (Equations (1) and (2)):

$$
\begin{gathered}
\mathrm{CuS}+2 \mathrm{NH}_{3}+2 \mathrm{O}_{2} \rightarrow \mathrm{Cu}\left(\mathrm{NH}_{3}\right)_{2}{ }^{2+}+\mathrm{SO}_{4}{ }^{2-}, \\
\mathrm{Cu}\left(\mathrm{NH}_{3}\right)_{2}{ }^{2+}+2 \mathrm{NH}_{3} \rightarrow \mathrm{Cu}\left(\mathrm{NH}_{3}\right)_{4}{ }^{2+}, \\
\mathrm{Ag}_{2} \mathrm{O}+4 \mathrm{NH}_{3}+\mathrm{H}_{2} \mathrm{O} \rightarrow 2\left[\mathrm{Ag}\left(\mathrm{NH}_{3}\right)_{2}\right]^{+}+2 \mathrm{OH}^{-}, \\
2 \mathrm{Ag}+2 \mathrm{NH}_{3}+0.5 \mathrm{O}_{2}+\mathrm{H}_{2} \mathrm{O} \rightarrow 2\left[\mathrm{Ag}\left(\mathrm{NH}_{3}\right)_{2}\right]^{+}+2 \mathrm{OH}^{-} .
\end{gathered}
$$

Ammonia is also considered an attractive leaching agent because of its low toxicity, low cost and ease of regeneration by evaporation from alkaline solutions [24]. Selectivity is an important advantage of the ammonia medium in hydrometallurgy, meaning that the desired metals can be dissolved and the undesired iron segregated in the same unit.

For many years, Alexander Mining (has plants using the "AmmLeach" technology in the Democratic Republic of the Congo and Australia) led the implementation and development of ammonia leaching for the recovery of copper from sulfide, oxidized ores and tailings, as well as the recovery of cobalt [25]. According to Alexander Mining, the key advantages of this technology include the ability to leach in atmospheric conditions, the low consumption of reagents to process acid-intensive materials, the ability to use standard equipment, high selectivity, and a low environmental impact.

The first industrial application of an ammonia leaching process related to the hydrometallurgical recovery of copper from oxidized ores was put into operation in 1916 [26]. Since that time, a large number of studies have been carried out to study the kinetics of leaching various copper ores and copper-containing wastes in ammonia media at atmospheric [27-31] and high pressure [32,33]. For example, Liu et al. [30] studied the leaching of calcareous bornite ore in a solution containing ammonia and ammonium persulfate. The study showed that copper recovery rises from 82.7 to $90.3 \%$ as the temperature increases from 303.15 to $333.15 \mathrm{~K}$. It was also revealed that copper recovery reaches $77.8 \%$ and $88.1 \%$ at ammonia concentrations of $1.0 \mathrm{~mol} / \mathrm{dm}^{3}$ and $2.5 \mathrm{~mol} / \mathrm{dm}^{3}$, respectively, and that an increase in the concentration of ammonium persulfate from $0.5 \mathrm{~mol} / \mathrm{dm}^{3}$ to $2.0 \mathrm{~mol} / \mathrm{dm}^{3}$ effects 
an increase in copper recovery from $80.9 \%$ to $90.3 \%$. Baba et al. [34] investigated the kinetics of leaching with ammonium sulfate solutions of complex covellite ore mined in Nigeria. It was revealed that the process was controlled by the diffusion kinetics, with an activation energy of $37.37 \mathrm{~kJ} / \mathrm{mol}$. In this case, copper recovery was $86.2 \%$ under optimal conditions.

Ammonia leaching with oxygen as an oxidizing agent was used commercially in 1954 to extract copper, nickel and cobalt from sulfide ores and concentrates by Sherritt Gordon [23] in Fort Saskatchewan. In the 1970s, Anaconda developed the Arbiter ammonia leaching process [24]. In one study [35], it was shown that for a concentrate containing $25 \%$ copper in the form of chalcopyrite in a solution of ammonium hydroxide and ammonium carbonate with the use of oxygen as an oxidizing agent under optimal conditions $\left(\mathrm{HH}_{4} \mathrm{OH}\right.$ concentration of $5 \mathrm{~mol} / \mathrm{dm}^{3} ;\left(\mathrm{NH}_{4}\right)_{2} \mathrm{CO}_{3}, 0.3 \mathrm{~mol} / \mathrm{dm}^{3} ; \mathrm{L} / \mathrm{S}$, 20 to 1 ; stirring speed, $1000 \mathrm{rpm}$; temperature, $333 \mathrm{~K}$; and oxygen flow rate, $1 \mathrm{dm}^{3} / \mathrm{min}$ ), only $70 \%$ of copper could be recovered into solution. A kinetic analysis of this process shows that the leaching rate was controlled by diffusion through the product layer, and the activation energy was $25 \mathrm{~kJ} / \mathrm{mol}$.

Ammonia leaching can also be used to extract precious metals. The ammonia-cyanide process was used commercially by Hunt to process tails from Comstock Lode in Nevada and copper-iron gold ores in Dale, California [36]. The industrial application of the Hunt process started in 2014, when ammonia leaching was introduced at the Gadabay plant [26].

Few studies, however, have focused on the kinetics of simultaneous copper and silver recovery by ammonia leaching from low-grade concentrates or ores under pressure [22,24,37]. Therefore, the aim of this work is to investigate the kinetics and mechanisms of the ammonia pressure leaching of low-grade sulfide raw materials containing copper and silver, in order to study the effects of Si-containing minerals on the kinetics of $\mathrm{Cu}$ and $\mathrm{Ag}$ leaching.

\section{Materials and Methods}

\subsection{Materials}

All the reagents used in this study were of analytical purity. A $25 \%$ ammonia solution was provided by JSC Azot (Kemerovo, Russia), and caustic soda was provided by JSC Bashkir Soda Company (Sterlitamak, Russia).

To achieve the required concentrations of solutions, ammonia and caustic alkali solutions were diluted with distilled water obtained on the apparatus manufactured by GFL GmbH (Burgwedel, Germany).

The original high-siliceous copper concentrate was provided by an ore processing plant at a Zhezkazgan mine, Kazakhstan [38]. The concentrate was obtained by a two-stage flotation enrichment (rougher and scavenger) of the initial low-grade ore containing $0.53 \%$ of copper and $12.53 \mathrm{ppm}$ of Ag. The yield of the concentrate was $7.09 \%$, while the copper recovery $93.7 \%$. The average particle size of the concentrate was $30 \mu \mathrm{m} ; 90 \%$ of the particles were smaller than $61 \mu \mathrm{m}$.

Table 1 shows the chemical composition of the obtained concentrate. Figure 1 shows an X-ray diffraction pattern of this concentrate. As can be seen from Table 1 and Figure 1, the initial concentrate contains a large amount of aluminosilicates and quartz, while the content of sulfur and copper does not exceed $5 \%$. It is obvious that the iron is partly present in oxidized form (chlorites).

Table 1. Chemical composition of initial low-grade copper-silver concentrate, wt. \%.

\begin{tabular}{cccccccc}
\hline $\mathbf{C u}$ & $\mathrm{Fe}$ & $\mathrm{S}$ & $\mathrm{SiO}_{2}$ & $\mathrm{Al}_{2} \mathbf{O}_{3}$ & $\mathrm{Na}_{2} \mathrm{O}$ & $\mathrm{Ag}$ & Other \\
\hline 7.0 & 8.2 & 5.7 & 55.1 & 10.5 & 2.2 & $140 \mathrm{ppm}$ & 11.3 \\
\hline
\end{tabular}




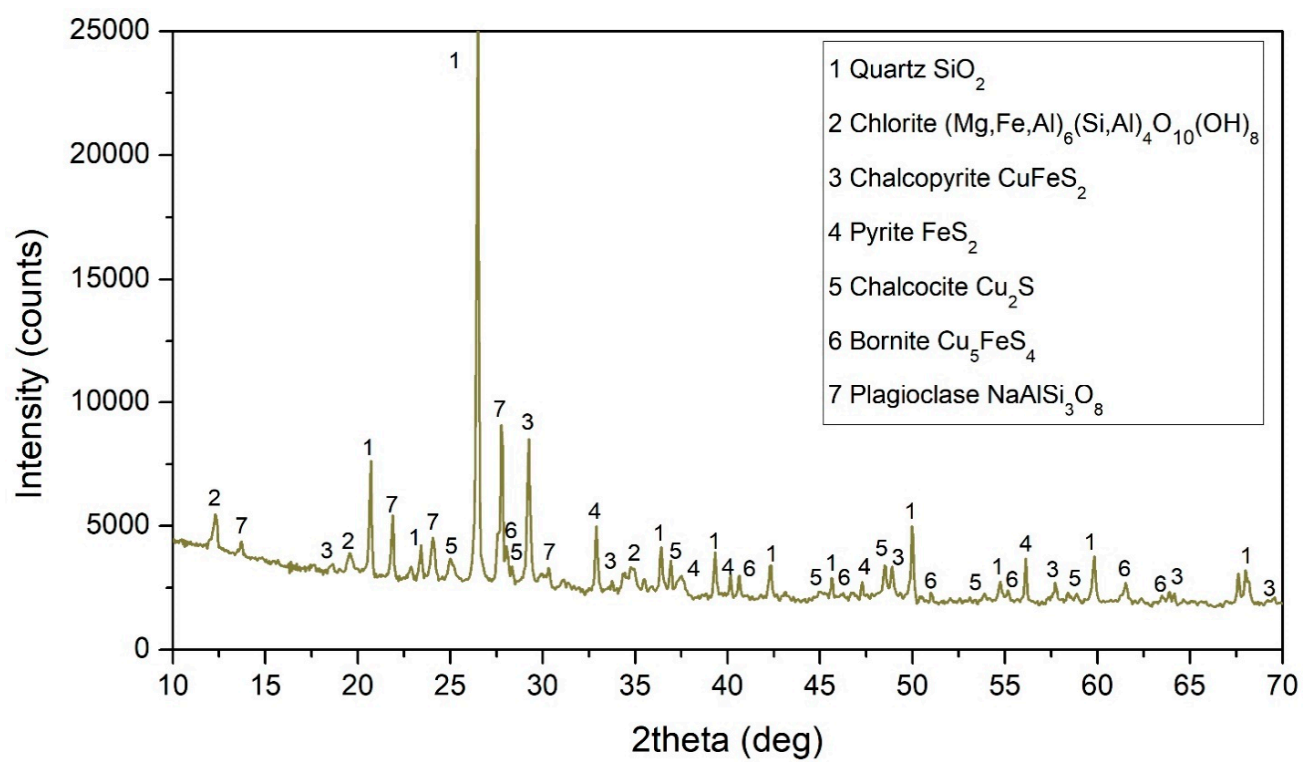

Figure 1. XRD pattern of initial low-grade copper-silver concentrate.

Table 2 shows the distribution of copper-containing minerals in the concentrate. The amount of oxidized copper was determined by leaching the initial concentrate in $10 \%$ sulfuric acid solution for $2 \mathrm{~h}$ at $95{ }^{\circ} \mathrm{C}$ without an oxidizing agent. The distribution of primary and secondary copper sulfides was determined by the x-ray analysis of the concentrate after the complete removal of aluminosilicates [39]. It can be seen that the largest part of the copper is represented by primary and secondary sulfides, but oxidized minerals are also present.

Table 2. Copper distribution in initial low-grade copper-silver concentrate, by minerals.

\begin{tabular}{cc}
\hline Copper Form. & Content, wt. $\%$ \\
\hline Primary sulfides & 14.7 \\
Secondary sulfides & 66.5 \\
Oxidized form & 18.8 \\
Total & 100 \\
\hline
\end{tabular}

\subsection{Analytical Methods}

The chemical analysis of the original material and the resulting solid products of the studied processes was performed using an Axios MAX X-ray fluorescence spectrometer (XRF) (Malvern Panalytical Ltd., Almelo, The Netherlands). The phase analysis was performed on an XRD 7000 Maxima diffractometer (Shimadzu Corp., Tokyo, Japan).

Scanning electron microscopy (SEM) was performed using a JSM-6390LV microscope (JEOL Ltd., Tokyo, Japan) equipped with a module for energy-dispersive X-ray spectroscopy analysis (EDX).

Samples from each experiment were taken at the selected time intervals, and the obtained solutions were analyzed using inductively coupled plasma mass spectrometry (ICP-MS-NexION $300 S$ quadrupole mass spectrometer, PerkinElmer Inc., Waltham, MA, USA).

\subsection{Experiments}

Laboratory experiments for $\mathrm{NaOH}$ and $\mathrm{NH}_{4} \mathrm{OH}$ leaching were carried out using a $0.6 \mathrm{dm}^{3}$ autoclave reactor (Parr Instrument, Moline, IL, USA), equipped with sample collection vessel. The reactor was thermostated. The materials were stirred using an overhead mixer at $700 \mathrm{rpm}$, which ensured a uniform density of the pulp and eliminated diffusion limitations. A portion of the raw material weighing $100 \mathrm{~g}$ was added to a prepared solution of $\mathrm{NaOH}\left(300 \mathrm{~g} / \mathrm{dm}^{3}\right)$ or $\mathrm{NH}_{4} \mathrm{OH}$ and 
$\left(\mathrm{NH}_{4}\right)_{2} \mathrm{SO}_{4}$ (with solution concentrations of $0.5 \mathrm{~mol} / \mathrm{dm}^{3}\left(\mathrm{NH}_{4}\right)_{2} \mathrm{SO}_{4}$ and $7 \mathrm{~mol} / \mathrm{dm}^{3} \mathrm{NH}_{3}$ ); the $\mathrm{L} / \mathrm{S}$ ratio in all the experiments was 5 to 1 . Then, the resulting pulp was heated in an autoclave with constant stirring. After the required temperature was reached, the oxygen supply and time countdown began. At the predetermined time intervals, a portion of the leaching pulp was taken with help of excessive pressure in reactor and cooled in a sealed vessel to atmospheric temperature. The obtained pulp was filtered in a Buchner funnel (ECROSKHIM Co., Ltd., St. Petersburg, Russia); the solutions were sent for ICP-MS analysis. At the end of experiment, the leaching cake was washed with distilled water, dried at $100{ }^{\circ} \mathrm{C}$ to a constant weight, weighed and sent for XRF analysis. All the experiments were performed twice, and the mean values are presented here.

\section{Results and Discussion}

\subsection{Leaching Kinetics of the Initial Concentrate}

The pressure leaching of sulfide copper concentrate in an ammonia environment is possible only in the presence of an additional oxidizing agent, necessary for the conversion of copper and silver into oxidized forms. However, even with a strong oxidizing agent, the efficiency of copper and silver recovery will strongly depend on the process temperature. In order to determine the limiting stage and to better understand the mechanisms of the reactions, we studied the kinetics of the ammonia leaching of a sample of the original concentrate at various temperatures and otherwise-equal conditions. The oxygen pressure in reactor was $0.6 \mathrm{MPa}$, and the total pressure was $0.9 \mathrm{MPa}$ at $120^{\circ} \mathrm{C}$ and $1.8 \mathrm{MPa}$ at $160^{\circ} \mathrm{C}$. The obtained leaching kinetic curves at various temperatures ranging from 120 to $160{ }^{\circ} \mathrm{C}$ are shown in Figure 2.

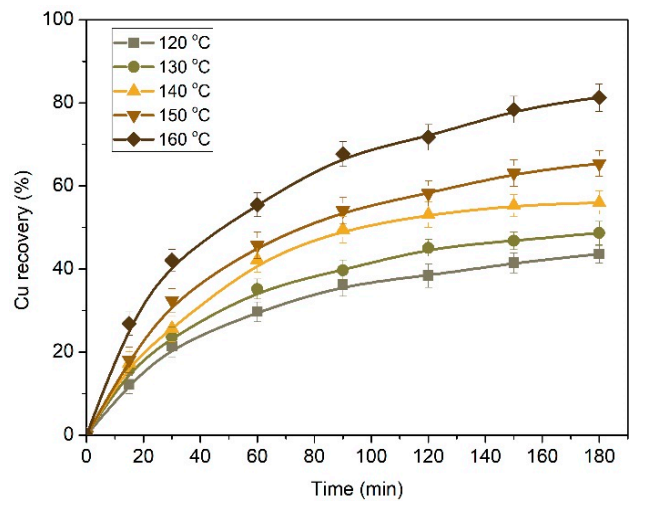

(a)

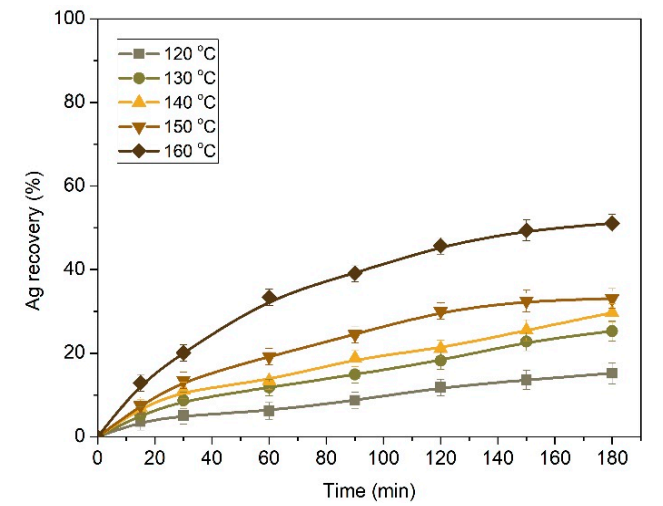

(b)

Figure 2. Effect of temperature and ammonia leaching duration on the degree of $\mathrm{Cu}$ (a) and $\mathrm{Ag}$ (b) recovery into solution.

Figure 2a shows that as temperature the increased from 120 to $160^{\circ} \mathrm{C}$, the degree of copper recovery into solution increased significantly. After $3 \mathrm{~h}$ of leaching at $120^{\circ} \mathrm{C}$, the degree of copper recovery into the solution is $36.0 \%$ and reaches $81.3 \%$ at $160{ }^{\circ} \mathrm{C}$ within the same amount of time. The degree of silver recovery also increases (Figure $2 \mathrm{~b}$ ). However, unlike copper, silver can be effectively recovered into solution only at temperatures above $160^{\circ} \mathrm{C}$. After $3 \mathrm{~h}$ of leaching at $160^{\circ} \mathrm{C}$, the recovery of silver in the solution was $51.1 \%$, while at below $130{ }^{\circ} \mathrm{C}$, it did not exceed $15-16 \%$. According to published data [28], oxidized copper leaches quite efficiently into an ammonia solution, even at atmospheric pressure. The oxidation rate for copper sulfides in an ammonia solution in autoclave conditions is also quite high, even at temperatures below $140{ }^{\circ} \mathrm{C}[22,35]$, which means that the process under study has certain limitations.

As shown in Figure 3, the corresponding experimental data for the leaching of silver and copper from the initial concentrate were linearized using various shrinking core models (SCM) [40-42] (Table 3), and the most adequate one proved to be the internal diffusion model, $1-2 / 3 \alpha-(1-\alpha)^{2 / 3}=\mathrm{Kt}$, where $\alpha$ 
is the degree of component recovery into the solution, $\mathrm{K}$ is the reaction rate constant $\left(\mathrm{min}^{-1}\right)$ and $\mathrm{t}$ is the duration (min). This result indicates that the leaching of copper and silver is limited by the rate of the supply of oxygen or a leaching reagent to the reaction surface through a layer of the product or unreacted substance.

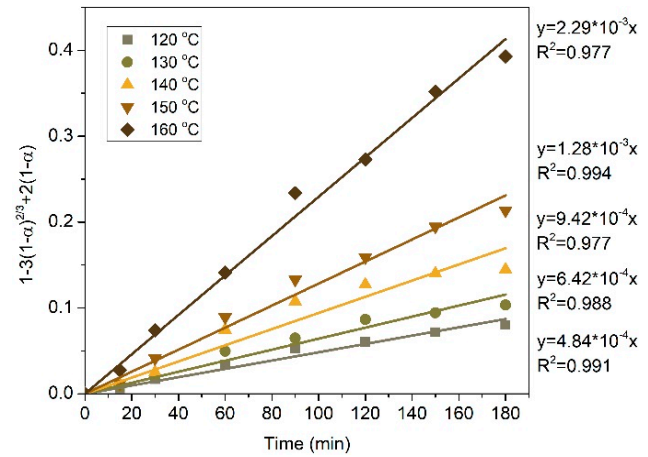

(a)

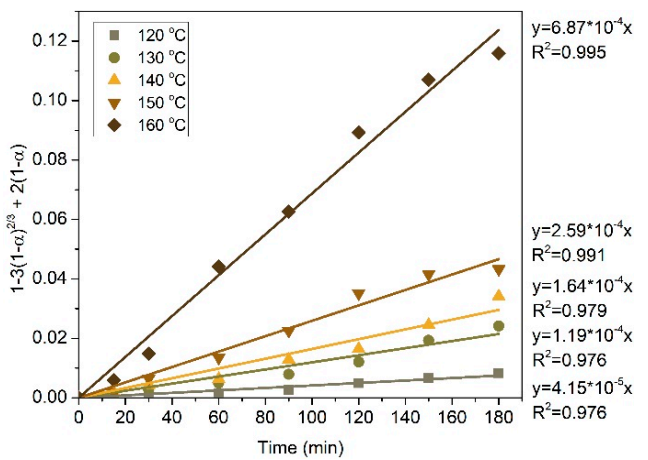

(b)

Figure 3. Dependence of $1-2 / 3 \alpha-(1-\alpha)^{2 / 3}$ on time for $\mathrm{Cu}(\mathbf{a})$ and $\mathrm{Ag}(\mathbf{b})$ recovery into solution.

Table 3. SCM equation fitting for $\mathrm{Cu}$ recovery from the initial low-grade concentrate.

\begin{tabular}{|c|c|c|c|c|c|c|c|}
\hline \multirow{2}{*}{$\#$} & \multirow{2}{*}{ Limiting step } & \multirow{2}{*}{ Equation } & \multicolumn{5}{|c|}{$\mathbf{R}^{2}$} \\
\hline & & & $120^{\circ} \mathrm{C}$ & $130^{\circ} \mathrm{C}$ & $140^{\circ} \mathrm{C}$ & $150^{\circ} \mathrm{C}$ & $160^{\circ} \mathrm{C}$ \\
\hline 1 & Diffusion through the product layer (sp) & $1-3(1-\alpha)^{2 / 3}+2(1-\alpha)$ & 0.991 & 0.988 & 0.977 & 0.994 & 0.977 \\
\hline 2 & Diffusion through the liquid film (sp) & $\alpha$ & 0.667 & 0.662 & 0.626 & 0.625 & 0.610 \\
\hline 3 & Surface chemical reactions $(\mathrm{sp})$ & $1-(1-\alpha)^{1 / 3}$ & 0.750 & 0.729 & 0.805 & 0.737 & 0.845 \\
\hline 4 & New shrinking core model & $1 / 3 \ln (1-\alpha)+\left[(1-\alpha)^{-1 / 3}-1\right]$ & 0.989 & 0.993 & 0.960 & 0.989 & 0.968 \\
\hline 5 & Hybrid (1st equation +3 rd equation) & $\left(1-3(1-\alpha)^{2 / 3}+2(1-\alpha)\right)+\left(1-(1-\alpha)^{1 / 3}\right)$ & 0.855 & 0.846 & 0.841 & 0.846 & 0.947 \\
\hline
\end{tabular}

$\mathrm{sp}$-spherical particles; $\alpha$-the degree of Cu recovery into the solution.

Figure 4 shows a plot of lnk versus the inverse of temperature, $1 / \mathrm{T}\left(\mathrm{K}^{-1}\right)$. In accordance with the Arrhenius equation, the slope of the straight line in Figure 4 was used to determine the apparent activation energy of the leaching of copper and silver as $53.50 \mathrm{~kJ} / \mathrm{mol}$ and $90.35 \mathrm{~kJ} / \mathrm{mol}$, respectively. It follows that the silver leaching reaction requires higher activation energies than copper leaching. This is probably due to the fact that the copper in the initial material is represented by various minerals, including oxides, some easily soluble at lower temperatures. By contrast, silver and a certain part of sulfide copper are more refractory. It is also possible that the copper and silver minerals are finely impregnated in the aluminosilicate rock, resulting in diffusion limitations. As shown before [43], a high value of the activation energy is not always representative of a kinetically controlled reaction.

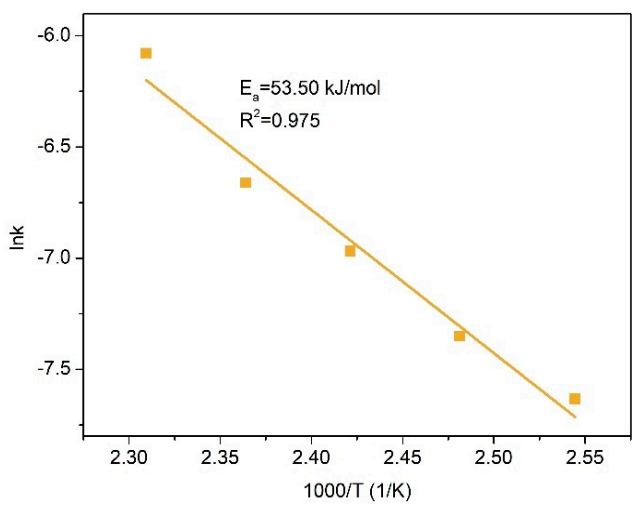

(a)

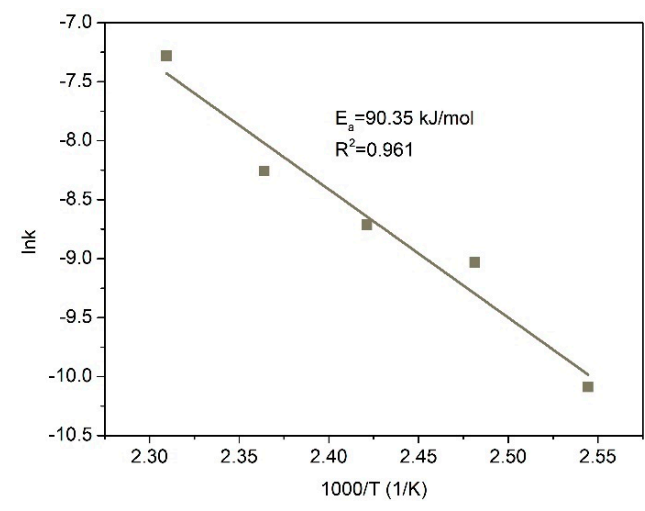

(b)

Figure 4. Dependence of lnk-1000/T for the recovery of copper (a) and silver (b) into solution.

To reveal the effect of aluminosilicates on the mechanism of leaching, electron micrograph and EDX analyses of the initial concentrate particles (Figure 5) were performed. According to Figure 5, 
there are two types of grain with different morphologies in the initial concentrate: grains with a smooth surface with ultrafine particles scattered on them and grains with a rough surface. The result of the EDX analysis (Table 4) shows that the first type of grain is most likely a sulfide mineral. The EDX analysis also indicates that sulfides are bound to aluminosilicates by mutual germination, since silicon is distributed, although unevenly, over the entire surface, including at accumulations of copper and silver. At the same time, silver is inextricably linked with copper accumulation areas.

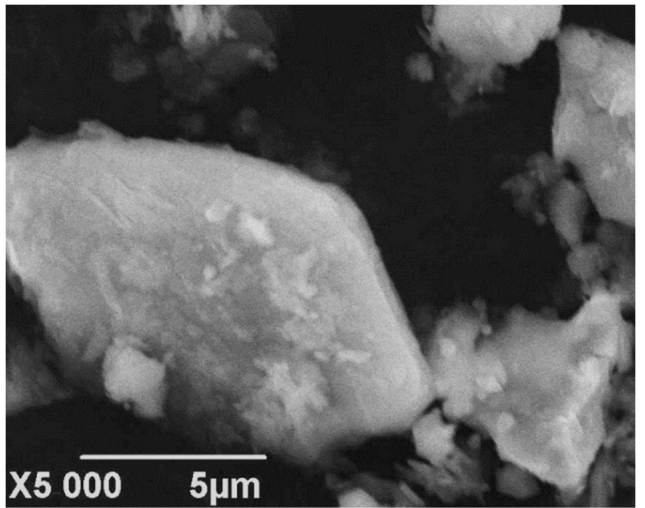

(a)

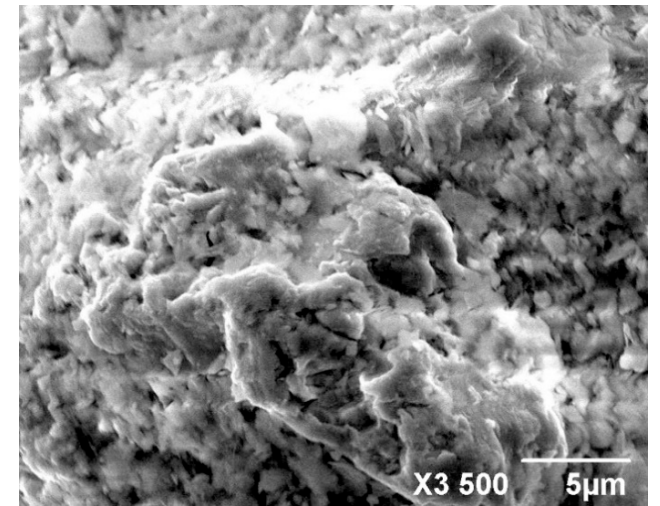

(b)

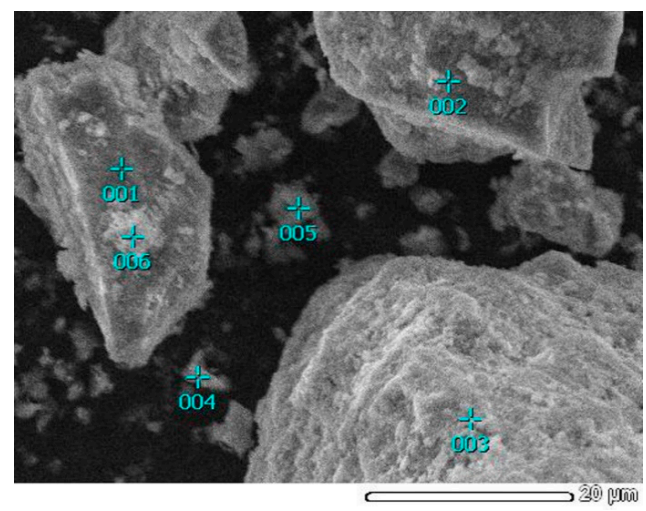

(c)

Figure 5. SEM images of typical grains of the initial concentrate $(\mathbf{a}, \mathbf{b})$ and SEM image with the position of an EDX spectrum (c).

Table 4. The elemental compositions (energy-dispersive X-ray spectroscopy analysis (EDX) spectrum) of the initial concentrate, wt. \%.

\begin{tabular}{ccccccccc}
\hline Element & Al & Si & S & Fe & Cu & Ag & O & Total \\
\hline Figure 5c. Point 001 & 2.78 & 21.07 & 2.83 & 18.39 & 18.60 & 0.15 & 36.16 & 100 \\
Figure 5c. Point 002 & 3.10 & 32.29 & 0.29 & 11.12 & 7.24 & 0.00 & 45.96 & 100 \\
Figure 5c. Point 003 & 3.58 & 40.46 & 0.00 & 2.92 & 1.89 & 0.00 & 51.15 & 100 \\
Figure 5c. Point 004 & 2.91 & 10.43 & 0.62 & 27.41 & 26.33 & 0.50 & 31.80 & 100 \\
Figure 5c. Point 005 & 1.49 & 5.61 & 0.29 & 53.19 & 7.29 & 0.00 & 32.13 & 100 \\
Figure 5c. Point 006 & 4.40 & 14.31 & 5.74 & 12.16 & 34.85 & 0.83 & 27.71 & 100 \\
\hline
\end{tabular}

Thus, we can assume the inhibitory effect of aluminosilicates, as their layer on the particle surface prevents the diffusion of oxygen and ammonia. Aluminosilicates can also adsorb non-ferrous metals from solution $[44,45]$. Therefore, the direct pressure ammonia leaching of the concentrate without pre-treatment does not allow copper and silver recovery from a low-grade concentrate into the solution at temperatures below $160^{\circ} \mathrm{C}$, which is explained by the diffusion limitations created by a layer of aluminosilicates on the surface of sulfides. 
In order to remove the passivating effect of aluminosilicates, one can use physical (mechanical activation, fusion) and chemical methods (preliminary alkaline desilication). Therefore, to further study the effect of aluminosilicates on copper and silver recovery into an ammonia solution, we studied the process kinetics after extracting silica from the original material by pressure alkaline leaching.

\subsection{Effect of Preliminary Desilication on Ammonia Leaching of Low-Grade Copper-Silver Concentrate}

To exclude the possible effects of silica-containing minerals, we investigated the preliminary removal of silicon from the concentrate by pressure alkaline leaching under the following conditions: $\mathrm{NaOH}=300 \mathrm{~g} / \mathrm{dm}^{3}, \mathrm{~L} / \mathrm{S}=5: 1, \mathrm{t}=200{ }^{\circ} \mathrm{C}$, total pressure $=1.5 \mathrm{MPa}$, and duration $=2 \mathrm{~h}$ [39]. The method allowed the recovery of $63 \%$ of the silicon into the solution, while the cake had the following composition (Table 5):

Table 5. Chemical composition of desilicated copper concentrate, wt. \%.

\begin{tabular}{cccccccc}
\hline $\mathbf{C u}$ & $\mathrm{Fe}$ & $\mathbf{S}$ & $\mathrm{SiO}_{\mathbf{2}}$ & $\mathbf{A l}_{\mathbf{2}} \mathbf{O}_{3}$ & $\mathrm{Na}_{\mathbf{2}} \mathbf{O}$ & $\mathrm{Ag}$ & Other \\
\hline 10.7 & 12.6 & 8.7 & 30.5 & 15.1 & 8.8 & $210 \mathrm{ppm}$ & 13.6 \\
\hline
\end{tabular}

3.2.1. Kinetics of Copper and Silver Leaching from a Concentrate after Preliminary Desilication

The effect of temperature and the duration of leaching on copper and silver recovery from a desilicated concentrate is shown in Figure 6.

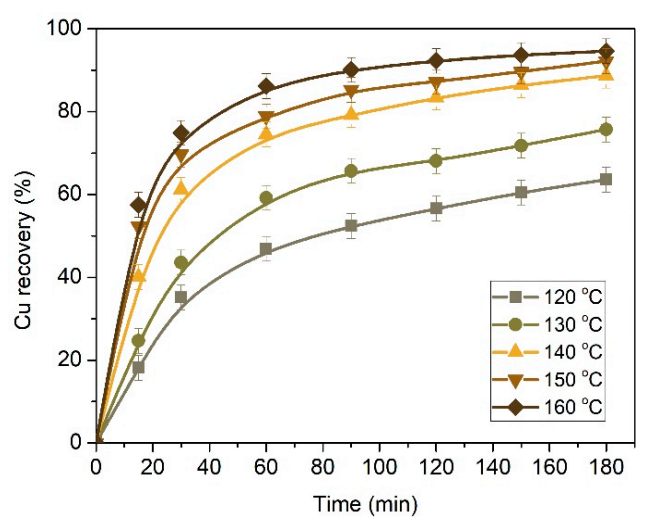

(a)

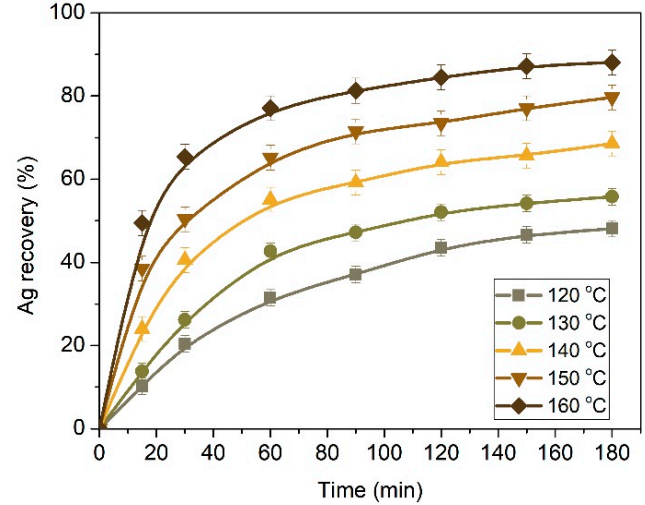

(b)

Figure 6. Dependence of the recovery of copper (a) and silver (b) into the solution on the temperature and duration of leaching of desilicated concentrate.

Figure 6 shows that, as in the case of the initial concentrate, the temperature has a significant effect on the speed of the process; after 60 min of leaching, copper recovery increases from $63 \%$ to $94 \%$. A significant influence of the duration in the range 0-60 min is observed at all studied temperatures; after $60 \mathrm{~min}$, the rate of $\mathrm{Cu}$ and Ag recovery in the solution decreases significantly, which is most likely due to diffusion limitations. Nevertheless, the rate of $\mathrm{Cu}$ and $\mathrm{Ag}$ recovery into solution from a desilicated concentrate is much higher, especially clearly seen in case of silver and apparently associated with a decrease in the passivating or sorption effect of aluminosilicates after desilication and with an increase in the surface area of sulfide particles that are in contact with solvent.

As shown in Figure 7, the corresponding experimental data on $\mathrm{Cu}$ and $\mathrm{Ag}$ leaching from a desilicated concentrate were also linearized using various shrinking core models. In this case, the most adequate was a new model proposed by Dickinson and Heal [40], $1 / 3 \ln \left(1-\alpha+\left((1-\alpha)^{-1 / 3}-1\right)=k t\right.$, where $\alpha$ is the degree of a component's recovery into solution, $\mathrm{k}$ is the reaction rate constant $\left(\mathrm{min}^{-1}\right)$, and $t$ is the duration ( $\mathrm{min}$ ). This result indicates that the leaching of copper and silver is limited by the rate of the supply of oxygen or leaching agent to the reaction surface through the interfacial transfer 
and diffusion across the product layer. Thus, we can assume that in this case, the process mode changes: interfacial transfer is added to the internal diffusion.

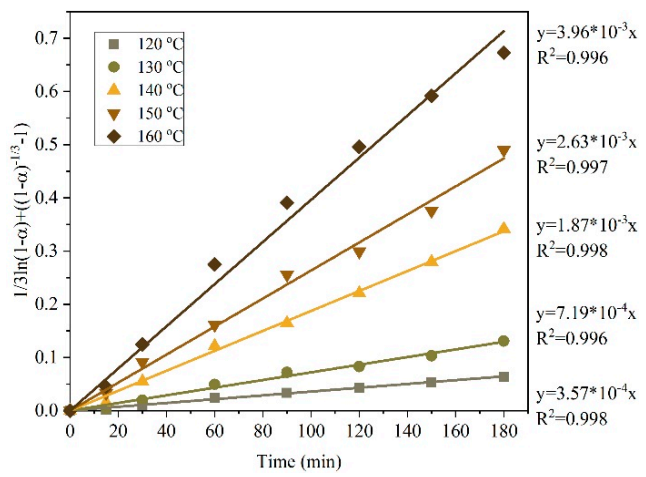

(a)

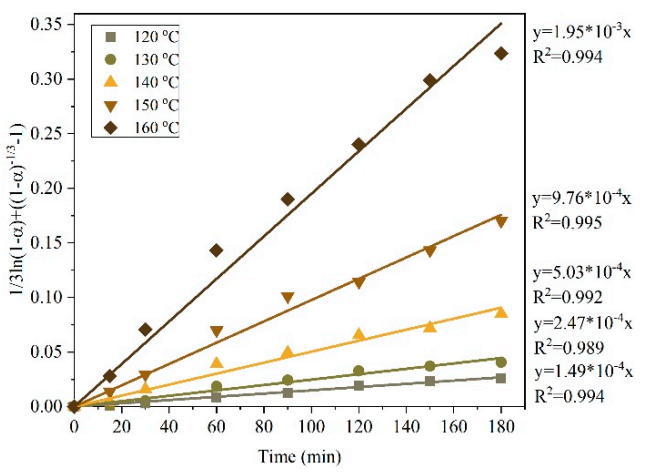

(b)

Figure 7. Dependence of $1 / 3 \ln \left(1-\alpha+\left((1-\alpha)^{-1 / 3}-1\right)\right.$ on time for $\mathrm{Cu}(\mathbf{a})$ and $\mathrm{Ag}(\mathbf{b})$ recovery into solution.

Based on the slope of the straight line in Figure 8, the apparent activation energy of the leaching is $86.76 \mathrm{~kJ} / \mathrm{mol}$ for $\mathrm{Cu}$ and $92.15 \mathrm{~kJ} / \mathrm{mol}$ for $\mathrm{Ag}$, respectively. This indicates an increase in the effect of temperature on the leaching of copper.

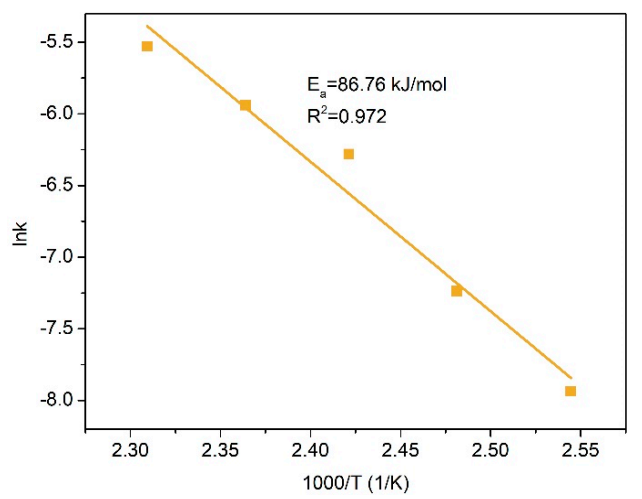

(a)

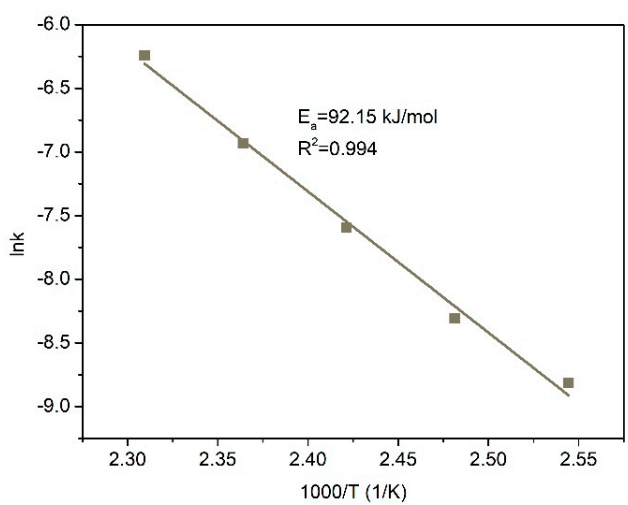

(b)

Figure 8. Dependence of lnk-1000/T for the recovery of copper (a) and silver (b) into solution from a desilicated concentrate.

The obtained high value of the activation energy along with the high degree of description of the kinetic curves by the new SCM equation, which is applicable for the processes restricted by the supply of reagents through the diffusion layer, indicates a complex mechanism of the autoclave leaching of copper and silver in an ammonia environment.

The SCM can only be used to determine the average values of the activation energy, which may lead to the omission of some reaction features. The time-to-a-given-fraction method [46] was used to calculate the apparent activation energy at different points in the leaching process. The time required to achieve a certain degree of leaching and the apparent activation energy, $\mathrm{E}_{\mathrm{a}}$, are related according to Equation (5).

$$
\ln \mathrm{t}_{\mathrm{x}}=\mathrm{const}-\ln \mathrm{A}+\mathrm{E}_{\mathrm{a}} / \mathrm{RT},
$$

The slope of the graph plotted with $\operatorname{lnt}_{\mathrm{x}}$ and 1000/T coordinates allows one to calculate the apparent activation energy.

The calculation of activation energy by the graphical method was performed as shown in Figure 9. 


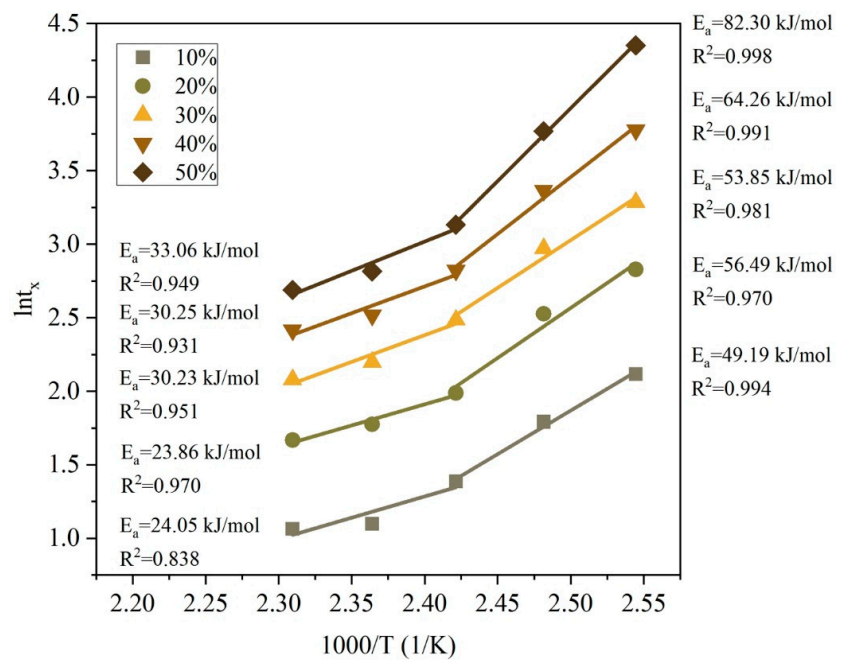

Figure 9. Dependence of $\operatorname{lnt}_{\mathrm{x}}$ on 1000/T for various degrees of recovery of copper.

According to Figure 9, the calculated values of the apparent activation energy according to the time-to-a-given-fraction method change from 39.77 to $60.95 \mathrm{~kJ} / \mathrm{mol}$ as the degree of copper recovery into the solution increases from $10 \%$ to $50 \%$. These values are lower than the activation values obtained earlier in the SCM model. The low activation energies in the initial period of the ammonia pressure leaching of copper from desilicated concentrate is explained by the increased dissolution rates for less refractory oxidized compounds and secondary copper sulfides. Additionally, there seems to be a change in the slope of the curves at $140{ }^{\circ} \mathrm{C}(2.42 \mathrm{1} / \mathrm{K})$, suggesting a change in the rate-determining mechanism at higher temperatures. It can be assumed that the effect of kinetic difficulties at low temperatures may be higher. Chalcocite is dissolved according to the following reactions (Equations (6) and (7)):

$$
\begin{gathered}
2 \mathrm{Cu}_{2} \mathrm{~S}+4 \mathrm{NH}_{4} \mathrm{OH}+2\left(\mathrm{NH}_{4}\right)_{2} \mathrm{SO}_{4}+\mathrm{O}_{2}=2 \mathrm{Cu}\left(\mathrm{NH}_{3}\right)_{4} \mathrm{SO}_{4}+2 \mathrm{CuS}+6 \mathrm{H}_{2} \mathrm{O} \\
\mathrm{CuS}+4 \mathrm{NH}_{4} \mathrm{OH}+2 \mathrm{O}_{2}=\mathrm{Cu}\left(\mathrm{NH}_{3}\right)_{4} \mathrm{SO}_{4}+4 \mathrm{H}_{2} \mathrm{O}
\end{gathered}
$$

The dissolution of covellite and other refractory sulfides (chalcopyrite, bornite) at subsequent stages of leaching occurs at lower rates due to lower solubility, which explains the increase in activation energy [47].

The efficiency of copper and silver recovery will strongly depend on the oxygen pressure [24]. The effect of oxygen pressure in the range of 0.2 to $0.8 \mathrm{MPa}$ on copper recovery at a leaching temperature of $140{ }^{\circ} \mathrm{C}$ is shown in Figure 10.

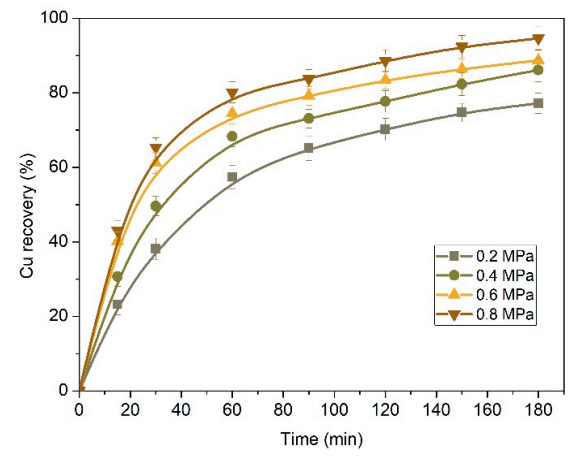

(a)

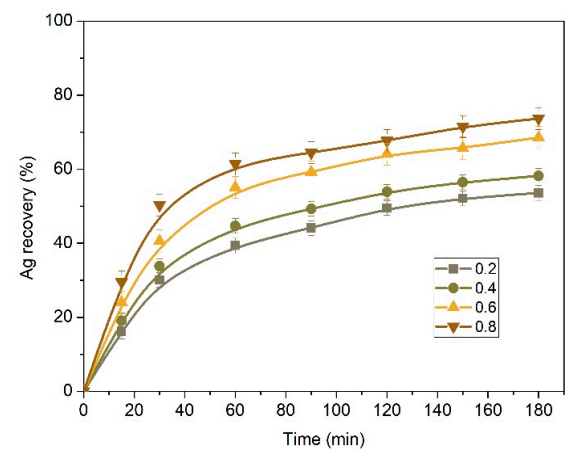

(b)

Figure 10. Dependence of $\mathrm{Cu}(\mathbf{a})$ and $\mathrm{Ag}(\mathbf{b})$ recovery on oxygen pressure and duration (temperature: $\left.140{ }^{\circ} \mathrm{C}\right)$. 
The results in Figure 10 show the positive effect of an increase in oxygen pressure on the recovery of $\mathrm{Cu}$ and $\mathrm{Ag}$ into solution. As the oxygen pressure increases from 0.2 to $0.8 \mathrm{MPa}$, copper recovery increases from $77.2 \%$ to $93.6 \%$ over 180 min of leaching, and silver recovery increases from $53.6 \%$ to $73.7 \%$. An increase in the process duration for the entire studied range also positively affects the transition of $\mathrm{Cu}$ and $\mathrm{Ag}$ into solution. The final concentration of copper in the solution at an oxygen pressure of $0.8 \mathrm{MPa}$ was $20.3 \mathrm{~g} / \mathrm{dm}^{3}$, and the concentration of $\mathrm{Ag}$ was $0.4 \mathrm{mg} / \mathrm{dm}^{3}$. This solution can be used for the extraction of valuable metals. The final concentration of iron in the solution in all the experiments was $0.6-1 \mathrm{mg} / \mathrm{dm}^{3}$.

Using the slopes of the straight lines obtained by substituting data for $\mathrm{Cu}$ and $\mathrm{Ag}$ recovery at oxygen pressures of $0.2-0.8 \mathrm{MPa}$ and a temperature of $140{ }^{\circ} \mathrm{C}$ into the new SCM (Figure $11 \mathrm{a}, \mathrm{b}$ ), we plotted a graph with the $\ln \mathrm{k}_{\mathrm{c}}-\ln \mathrm{P}_{\mathrm{o} 2}$ coordinates to determine the partial order with respect to oxygen pressure (Figure 11c,d) [47]. As a result, the empirical orders with respect to oxygen pressure were 0.959 for $\mathrm{Cu}$ and 0.932 for $\mathrm{Ag}$, both close to 1, which may also indicate external diffusion limitations [48].

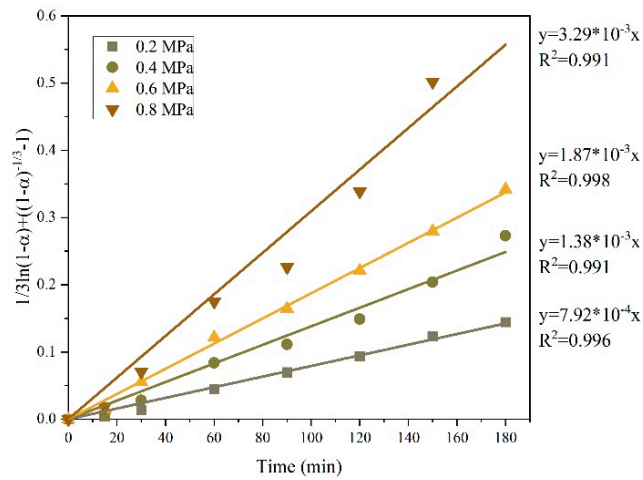

(a)

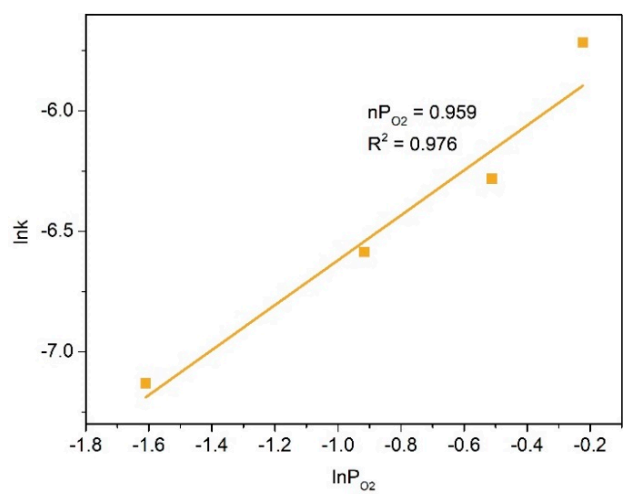

(c)

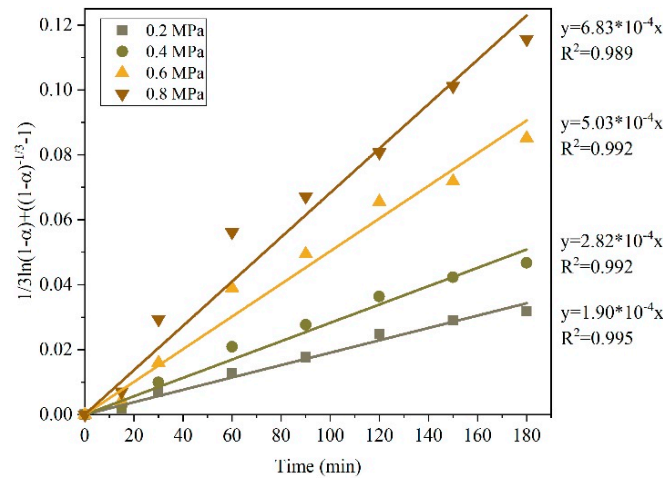

(b)

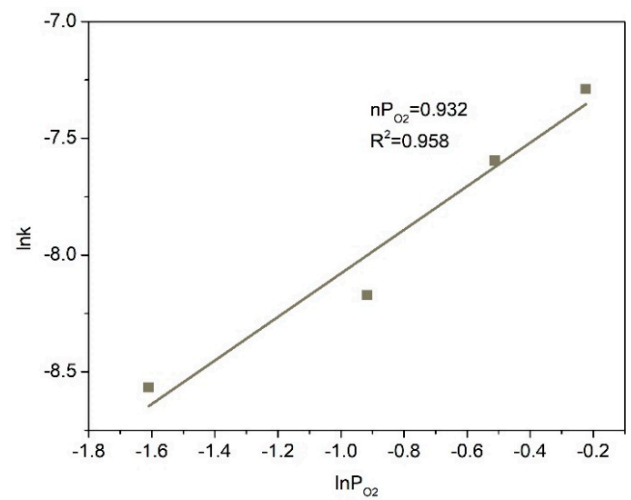

(d)

Figure 11. Dependence of $1 / 3 \ln (1-\alpha)+\left((1-\alpha)^{-1 / 3}-1\right)$ on oxygen pressure for $\mathrm{Cu}(\mathbf{a})$ and $\mathrm{Ag}$ (b) recovery into solution, and dependence of $\ln \mathrm{k}_{\mathrm{c}}$ on $\ln \mathrm{P}_{\mathrm{o} 2}$ to determine the oxygen order for $\mathrm{Cu}$ (c) and $\operatorname{Ag}(\mathbf{d})$.

\subsubsection{Characteristics of Solid Residue}

To study the effect of preliminary desilication on the mechanism of leaching, electron micrographs and maps of the surface (SEM-EDX) of solid residue particles obtained at oxygen pressures of $0.8 \mathrm{MPa}$ and a temperature of $140{ }^{\circ} \mathrm{C}$ after $3 \mathrm{~h}$ of leaching were examined. The SEM image and map-scans for the desilicated concentrate are presented in Figure 12. 


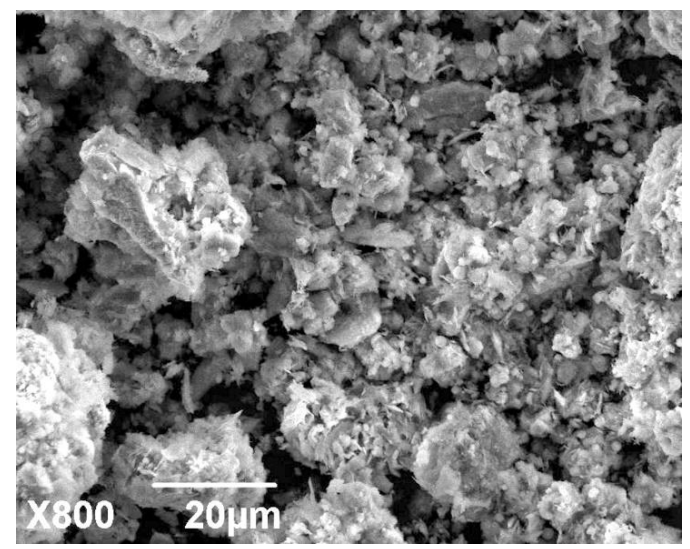

(a)

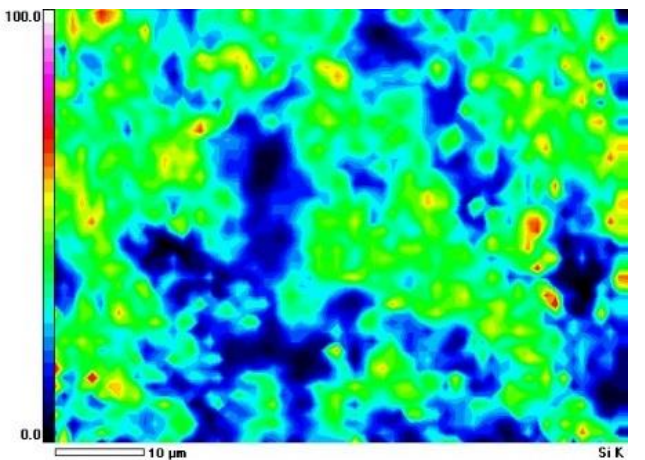

(b)

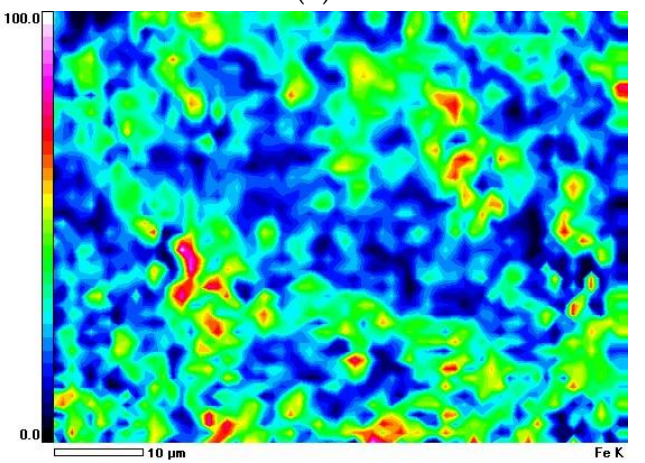

(d)

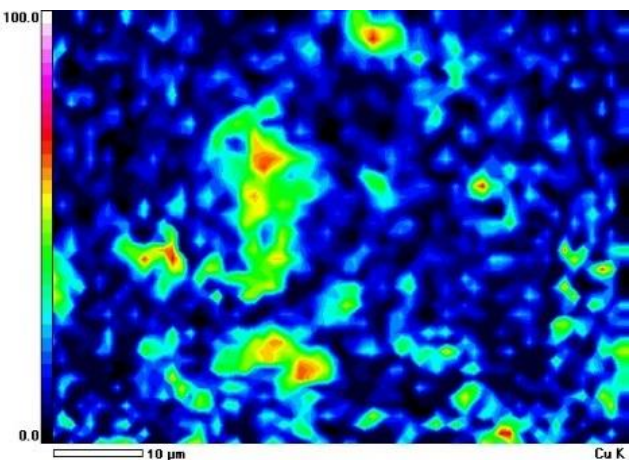

(c)

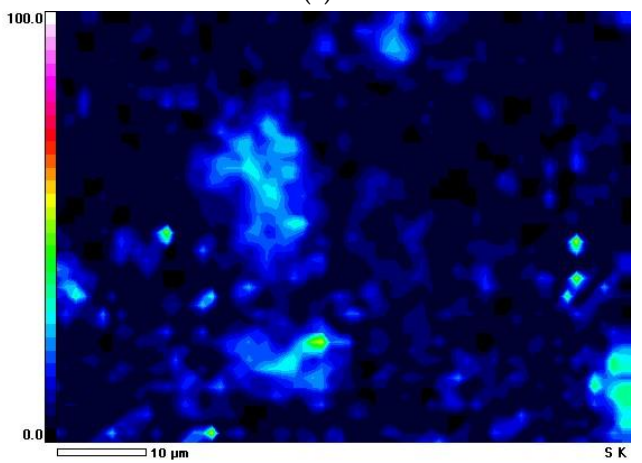

(e)

Figure 12. SEM image of desilicated concentrate (a), and map-scans $(\mathbf{b}-\mathbf{e})$ for $\mathrm{Si}, \mathrm{Cu}, \mathrm{Fe}$ and $\mathrm{S}$, respectively.

In contrast to the initial material, the cake after pressure desilication contains much less silica (Table 5), although it is also distributed over the entire surface, and has a heterogeneous surface with many cavities and voids (Figure 12a,b), which facilitates the access of reagents to sulfide minerals. The presence of pores is explained by the dissolution of Si-bearing minerals in an alkaline solution. Additionally, spherical particles are formed on the surface, which is associated with the precipitation of sodium hydroaluminosilicate [49]. However, sodium hydroaluminosilicate can also inhibit the process [50] but apparently to a lesser extent due to its high porosity. The existence of amorphous inclusions in the cake is confirmed by the presence of noise in the XRD pattern of the cake after desilication (Figure 13). In addition, the XRD pattern in Figure 13 shows that the main phases after desilication are cancrinite, quartz and pyrite, as well as a small amount of copper minerals. 


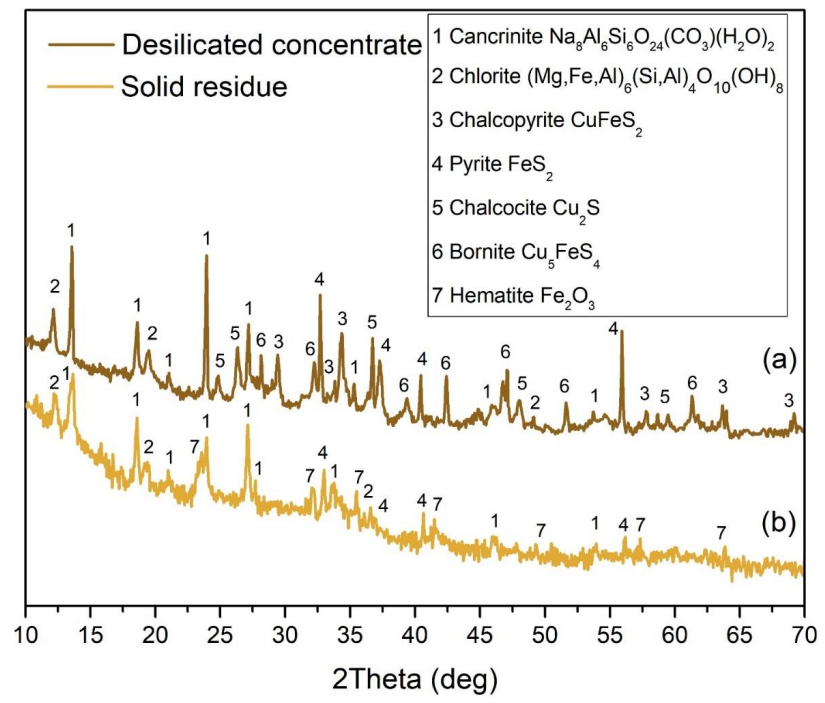

Figure 13. XRD pattern of desilicated concentrate (a), and the product of its leaching in ammonia solution (b).

The cakes after desilication have a relatively uniform distribution of the above elements, especially $\mathrm{Si}$, which is explained by the formation of sodium hydroaluminosilicates on the surface of copper and iron minerals (Figure 12b).

The cakes after the pressure ammonia leaching of desilicated concentrate were also analyzed by scanning electron microscopy to assess morphological changes. The SEM and map-scanning images obtained for the ammonia pressure leaching cake of the desilicated concentrate are presented in Figure 14.

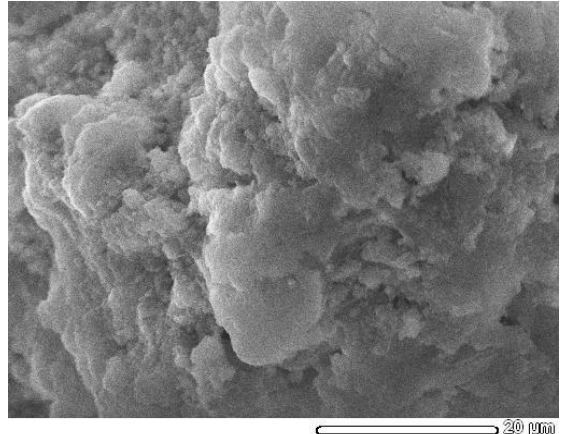

(a)

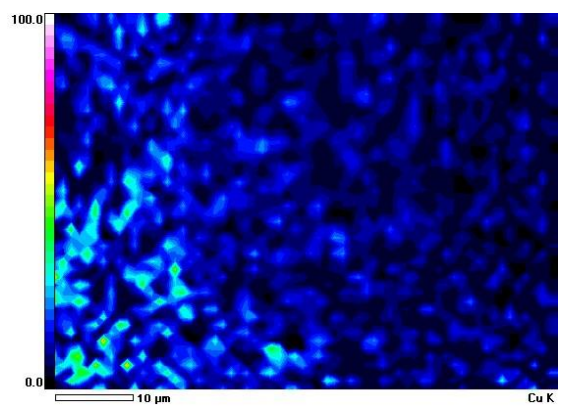

(c)

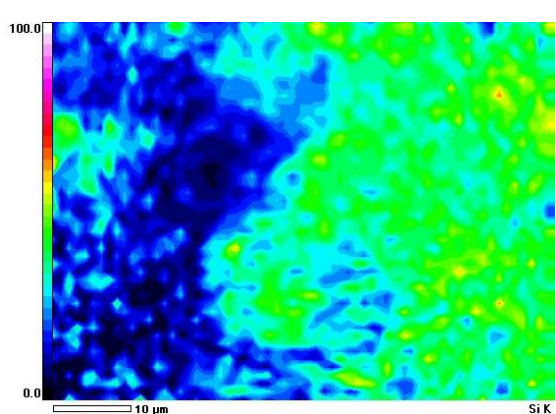

(b)

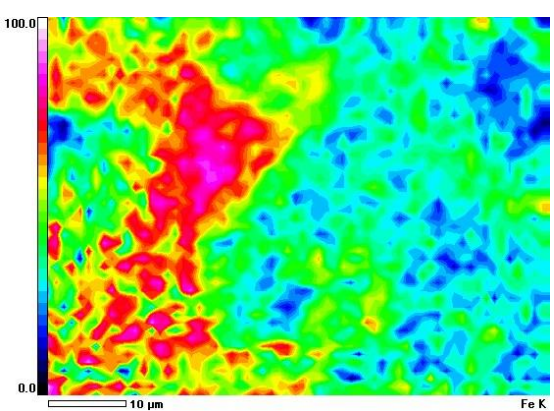

(d)

Figure 14. SEM image of ammonia leaching residue (a), and map-scans (b-d) for $\mathrm{Si}, \mathrm{Cu}$ and $\mathrm{Ag}$, respectively. 
According to the SEM images, the residue after ammonia pressure leaching is represented by particles larger than $30 \mu \mathrm{m}$ with a rough surface (Figure 14a). The diffraction pattern of this cake (Figure 13b) shows that cancrinite and hematite are the main minerals in the material.

The copper content decreases significantly after ammonia pressure leaching (Figure 14c). It follows that preliminary alkaline desilication makes it possible to reduce the diffusion limitations caused by aluminosilicates and quartz (into which sulfide minerals are apparently finely impregnated) due to the formation of a porous surface during leaching. A schematic diagram of the process is presented in Figure 15.

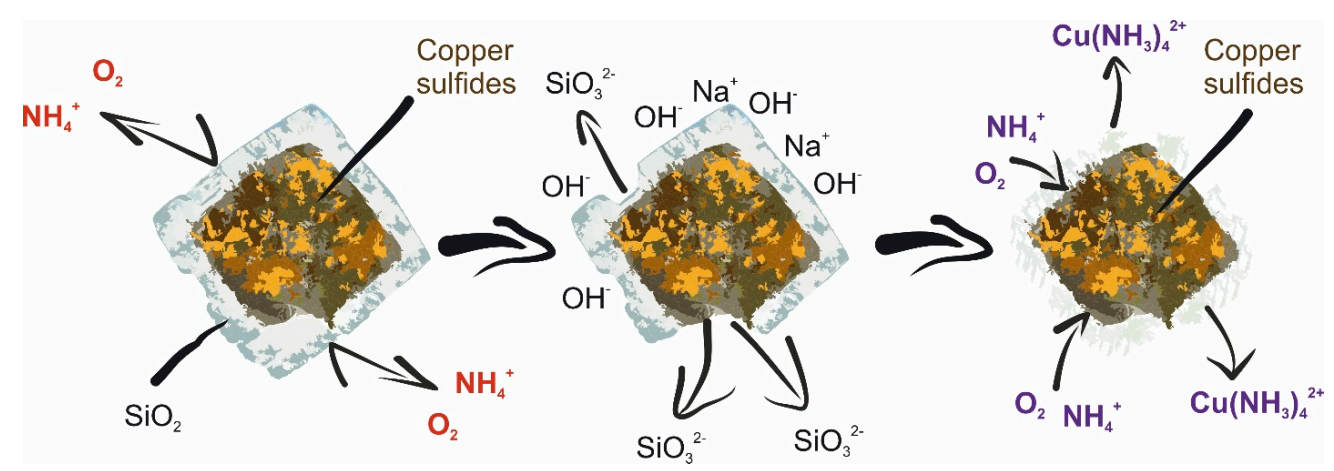

Figure 15. Schematic diagram of the effect of pre-desilication on recovery of $\mathrm{Cu}$ and Ag during ammonia leaching.

Thus, a new environmentally friendly method of processing such a low-grade copper-silver concentrate is proposed, eliminating the need for ultra-fine grinding, which leads to the formation of a large amount of fine and toxic waste. Silica that is converted to an alkaline solution, in turn, can be used to obtain additional valuable products. Ammonia can also be easily regenerated by distillation [31].

\section{Conclusions}

The effect of aluminosilicate minerals and their preliminary alkaline leaching on the ammonia pressure leaching of low-grade copper concentrates has been investigated. Using new methods for studying the kinetics of the processes, it has been shown that the limiting stage of the process changes over the course of the leaching. The following conclusions have been reached:

1. In addition to sulfide minerals of copper, the initial concentrate contains a large amount of oxidized copper and aluminosilicate compounds that coat valuable components, preventing their leaching into the solution.

2. The results of the experiments on the pressure leaching of the initial copper concentrate in an ammonium/ammonium-sulphate solution in the presence of oxygen are in good agreement with the shrinking core model in the intra-diffusion mode; the activation energies for copper and silver in this case were $53.50 \mathrm{~kJ} / \mathrm{mol}$ and $90.35 \mathrm{~kJ} / \mathrm{mol}$, respectively.

3. After the preliminary alkaline desilication of the concentrate, the recovery rate for $\mathrm{Cu}$ and Ag increases significantly, and the new shrinking core model proves to be the most adequate, indicating that the process is limited by diffusion through the product layer and interfacial diffusion. The partial order with respect to oxygen pressure is close to 1, which may also indicate external diffusion limitations. The activation energy of the process increases to $86.76 \mathrm{~kJ} / \mathrm{mol}$ for $\mathrm{Cu}$ and $92.15 \mathrm{~kJ} / \mathrm{mol}$ for $\mathrm{Ag}$.

4. Using the time-to-a-given-fraction method, it was shown that a high activation energy is necessary in the later stages of the process at low temperatures, when the most refractory sulfide minerals of $\mathrm{Cu}$ and $\mathrm{Ag}$ appear to be unleached. 
Author Contributions: Conceptualization, S.N.; methodology, K.K. and A.S.; validation, S.Z. and E.K.; formal analysis, K.K. and D.R.; investigation, A.S. and E.K.; resources, S.Z.; data curation, D.R.; writing-original draft preparation, K.K.; writing-review and editing, A.S. and S.N.; visualization, A.S. and E.K.; supervision, D.R.; project administration, S.Z.; funding acquisition, S.N. All authors have read and agreed to the published version of the manuscript.

Funding: This work was financially supported by the Russian Science Foundation Project No. 18-19-00186. The SEM-EDX analyses were funded by State Assignment, grant number 0836-2020-0020.

Acknowledgments: Technicians at the Ural Branch of Russian Academy of Sciences are acknowledged for their assistance with the XRD, XRF, SEM, EDS and ICP-MS analyses.

Conflicts of Interest: The authors declare no conflict of interest.

\section{References}

1. Peters, E. Hydrometallurgical process innovation. Hydrometallurgy 1992, 29, 431-459. [CrossRef]

2. Sinclair, L.; Thompson, J. In situ leaching of copper: Challenges and future prospects. Hydrometallurgy 2015, 157, 306-324. [CrossRef]

3. Ignatkina, V.A.; Bocharov, V.A.; Makavetskas, A.R.; Kayumov, A.A.; Aksenova, D.D.; Khachatryan, L.S.; Fishchenko, Y.Y. Rational Processing of Refractory Copper-Bearing Ores. Russ. J. NonFerr. Metals 2018, 59, 364-373. [CrossRef]

4. Singer, D.A. Future copper resources. Ore Geol. Rev. 2017, 86, 271-279. [CrossRef]

5. Palaniandy, S. Impact of mechanochemical effect on chalcopyrite leaching. Int. J. Miner. Process. 2015, 136, 56-65. [CrossRef]

6. Wang, G.; Yang, H.; Liu, Y.; Tong, L.; Auwalu, A. Study on the mechanical activation of malachite and the leaching of complex copper ore in the Luanshya mining area, Zambia. Int. J. Miner. Metall. Mater. 2020, 27, 292-300. [CrossRef]

7. Ye, X.; Gredelj, S.; Skinner, W.; Grano, S.R. Regrinding sulphide minerals-Breakage mechanisms in milling and their influence on surface properties and flotation behaviour. Powder Technol. 2010, 203, 133-147. [CrossRef]

8. Dong, Y.; Lin, H.; Xu, X.; Zhou, S. Bioleaching of different copper sulfides by Acidithiobacillus ferrooxidans and its adsorption on minerals. Hydrometallurgy 2013, 140, 42-47. [CrossRef]

9. Halinen, A.-K.; Rahunen, N.; Kaksonen, A.H.; Puhakka, J.A. Heap bioleaching of a complex sulfide ore. Hydrometallurgy 2009, 98, 92-100. [CrossRef]

10. Petersen, J. Heap leaching as a key technology for recovery of values from low-grade ores-A brief overview. Hydrometallurgy 2016, 165, 206-212. [CrossRef]

11. Watling, H.R. The bioleaching of sulphide minerals with emphasis on copper sulphides-A review. Hydrometallurgy 2006, 84, 81-108. [CrossRef]

12. Anderson, C.G.; Harrison, K.D.; Krys, L.E. Theoretical considerations of sodium nitrite oxidation and fine grinding in refractory precious-metal concentrate pressure leaching. Min. Metall. Explor. 1996, 13, 4-11. [CrossRef]

13. Rogozhnikov, D.A.; Mamyachenkov, S.V.; Anisimova, O.S. Nitric Acid Leaching of Copper-Zinc Sulfide Middlings. Metallurgist 2016, 60, 229-233. [CrossRef]

14. Rogozhnikov, D.A.; Kolmachikhin, B.V. Polymetallic Ore Concentration Middlings Nitric Acid Leaching Kinetics. SSP 2017, 265, 1065-1070. [CrossRef]

15. Xie, Y.; Xu, Y.; Yan, L.; Yang, R. Recovery of nickel, copper and cobalt from low-grade Ni-Cu sulfide tailings. Hydrometallurgy 2005, 80, 54-58. [CrossRef]

16. Ukraintsev, I.V.; Petrov, G.V.; Ivanov, B.S.; Boduen, A.Y. Autoclave conditioning of a low-grade sulphide copper concentrate. Tsm 2016, 10, 43-48. [CrossRef]

17. McDonald, R.G.; Muir, D.M. Pressure oxidation leaching of chalcopyrite. Part I. Comparison of high and low temperature reaction kinetics and products. Hydrometallurgy 2007, 86, 191-205. [CrossRef]

18. Cui, F.; Mu, W.; Wang, S.; Xin, H.; Xu, Q.; Zhai, Y.; Luo, S. Sodium sulfate activation mechanism on co-sulfating roasting to nickel-copper sulfide concentrate in metal extractions, microtopography and kinetics. Miner. Eng. 2018, 123, 104-116. [CrossRef]

19. Medvedev, A.S.; So, T.; Ptitsyn, A.M. Combined processing technology of the Udokan sulfide copper concentrate. Russ. J. NonFerr. Met. 2012, 53, 125-128. [CrossRef] 
20. Sun, X.; Chen, B.; Yang, X.; Liu, Y. Technological conditions and kinetics of leaching copper from complex copper oxide ore. J. Cent. South Univ. Technol. 2009, 16, 936-941. [CrossRef]

21. Dutrizac, J.E.; Jambor, J.L. Jarosites and Their Application in Hydrometallurgy. Rev. Mineral. Geochem. 2000, 40, 405-452. [CrossRef]

22. Boduen, A.Y.; Petrov, G.V.; Serebryakov, M.A. Investigation of ammonia autoclave leaching of silver and rhenium containing ill-conditioned copper concentrate. Tsm 2016, 10, 23-28. [CrossRef]

23. Forward, F.A.; Mackiw, V.N. Chemistry of the Ammonia Pressure Process for Leaching Ni, Cu, and Co from Sherritt Gordon Sulphide Concentrates. JOM 1955, 7, 457-463. [CrossRef]

24. Meng, X.; Han, K.N. The Principles and Applications of Ammonia Leaching of Metals-A Review. Mineral Process. Extr. Metall. Rev. 1996, 16, 23-61. [CrossRef]

25. MetaLeach. Available online: http://www.metaleach.com/ (accessed on 23 April 2020).

26. Hedjazi, F.; Monhemius, A.J. Industrial application of ammonia-assisted cyanide leaching for copper-gold ores. Miner. Eng. 2018, 126, 123-129. [CrossRef]

27. Baba, A.A.; Ghosh, M.K.; Pradhan, S.R.; Rao, D.S.; Baral, A.; Adekola, F.A. Characterization and kinetic study on ammonia leaching of complex copper ore. Trans. NonFerr. Met. Soc. China 2014, 24, 1587-1595. [CrossRef]

28. Bingöl, D.; Canbazoğlu, M.; Aydoğan, S. Dissolution kinetics of malachite in ammonia/ammonium carbonate leaching. Hydrometallurgy 2005, 76, 55-62. [CrossRef]

29. Liu, Z.; Yin, Z.; Hu, H.; Chen, Q. Dissolution kinetics of malachite in ammonia/ammonium sulphate solution. J. Cent. South Univ. Technol. 2012, 19, 903-910. [CrossRef]

30. Liu, Z.X.; Yin, Z.L.; Xiong, S.F.; Chen, Y.G.; Chen, Q.Y. Leaching and kinetic modeling of calcareous bornite in ammonia ammonium sulfate solution with sodium persulfate. Hydrometallurgy 2014, 144-145, 86-90. [CrossRef]

31. Radmehr, V.; Koleini, S.M.J.; Khalesi, M.R.; Tavakoli Mohammadi, M.R. Ammonia Leaching: A New Approach of Copper Industry in Hydrometallurgical Processes. J. Inst. Eng. India Ser. D 2013, 94, 95-104. [CrossRef]

32. Turan, M.D.; Arslanoğlu, H.; Altundoğan, H.S. Optimization of the leaching conditions of chalcopyrite concentrate using ammonium persulfate in an autoclave system. J. Taiwan Inst. Chem. Eng. 2015, 50, 49-55. [CrossRef]

33. Turan, M.D.; Altundoğan, H.S. Leaching of copper from chalcopyrite concentrate by using ammonium persulphate in an autoclave: Determination of most suitable impeller type by using response surface methodology. J. Cent. South Univ. 2013, 20, 622-628. [CrossRef]

34. Baba, A.A.; Balogun, A.F.; Olaoluwa, D.T.; Bale, R.B.; Adekola, F.A.; Alabi, A.G.F. Leaching kinetics of a Nigerian complex covellite ore by the ammonia-ammonium sulfate solution. Korean J. Chem. Eng. 2017, 34, 1133-1140. [CrossRef]

35. Nabizadeh, A.; Aghazadeh, V. Dissolution study of chalcopyrite concentrate in oxidative ammonia/ammonium carbonate solutions at moderate temperature and ambient pressure. Hydrometallurgy 2015, 152, 61-68. [CrossRef]

36. Muir, D.M. A review of the selective leaching of gold from oxidised copper-gold ores with ammonia-cyanide and new insights for plant control and operation. Miner. Eng. 2011, 24, 576-582. [CrossRef]

37. Boduen, A.Y.; Fokina, S.B.; Petrov, G.V.; Andreev, Y.V. Ammonia autoclave technology for the processing of low-grade concentrates generated in flotation concentration of cupriferous sandstones. Obogashchenie Rud 2019, 2, 33-38. [CrossRef]

38. Baranov, V.F. The use of foreign experience in the development of a reconstruction option for the Zhezkazgan concentration complex. Obogashchenie Rud 2020, 1, 54-59. [CrossRef]

39. Shoppert, A.A.; Loginova, I.V.; Pismak, V.N. Investigating of a Low-Grade Copper Concentrate Desilication by Alkali Pressure Leaching. MSF 2019, 946, 608-614. [CrossRef]

40. Dickinson, C.F.; Heal, G.R. Solid-liquid diffusion controlled rate equations. Thermochim. Acta 1999, 340-341, 89-103. [CrossRef]

41. Levenspiel, O. Chemical Reaction Engineering, 3rd ed.; Wiley: New York, NY, USA, 1999; ISBN 978-0-471-25424-9.

42. Rogozhnikov, D.A.; Shoppert, A.A.; Dizer, O.A.; Karimov, K.A.; Rusalev, R.E. Leaching Kinetics of Sulfides from Refractory Gold Concentrates by Nitric Acid. Metals 2019, 9, 465. [CrossRef] 
43. Baba, A.A.; Adekola, F.A. Hydrometallurgical processing of a Nigerian sphalerite in hydrochloric acid: Characterization and dissolution kinetics. Hydrometallurgy 2010, 101, 69-75. [CrossRef]

44. Karimov, K.A.; Rogozhnikov, D.A.; Naboichenko, S.S.; Karimova, L.M.; Zakhar'yan, S.V. Autoclave Ammonia Leaching of Silver from Low-Grade Copper Concentrates. Metallurgist 2018, 62, 783-789. [CrossRef]

45. Naboichenko, S.S. Avtoklavnaja Gidrometallurgija Cvetnych Metallov; GOU UGTU-UPI: Ekaterinburg, Russia, 2002; ISBN 978-5-321-00065-6.

46. Hidalgo, T.; Kuhar, L.; Beinlich, A.; Putnis, A. Kinetics and mineralogical analysis of copper dissolution from a bornite/chalcopyrite composite sample in ferric-chloride and methanesulfonic-acid solutions. Hydrometallurgy 2019, 188, 140-156. [CrossRef]

47. Tanda, B.C.; Eksteen, J.J.; Oraby, E.A. Kinetics of chalcocite leaching in oxygenated alkaline glycine solutions. Hydrometallurgy 2018, 178, 264-273. [CrossRef]

48. Lorenzo-Tallafigo, J.; Iglesias-Gonzalez, N.; Romero, R.; Mazuelos, A.; Carranza, F. Ferric leaching of the sphalerite contained in a bulk concentrate: Kinetic study. Miner. Eng. 2018, 125, 50-59. [CrossRef]

49. Smith, P. The processing of high silica bauxites-Review of existing and potential processes. Hydrometallurgy 2009, 98, 162-176. [CrossRef]

50. Wang, Y.; Li, X.; Zhou, Q.; Qi, T.; Liu, G.; Peng, Z.; Zhou, K. Effects of Si-bearing minerals on the conversion of hematite into magnetite during reductive Bayer digestion. Hydrometallurgy 2019, 189, 105126. [CrossRef]

(C) 2020 by the authors. Licensee MDPI, Basel, Switzerland. This article is an open access article distributed under the terms and conditions of the Creative Commons Attribution (CC BY) license (http://creativecommons.org/licenses/by/4.0/). 